\title{
OCENA NOŚNOŚCI DORAŹNEJ BELEK STALOWYCH WZMOCNIONYCH NAPRĘŻONYMI TAŚMAMI CFRP
}

\begin{abstract}
Dobre parametry wytrzymałościowe, niewielka gęstość, odporność na korozję jak również wysoka trwałość taśm kompozytowych CFRP stanowią o ich przewadze nad tradycyjnymi materiałami stosowanymi do wzmocnień konstrukcji stalowych. Wstępny naciąg taśm może dodatkowo zwiększyć efektywność wzmocnienia. $\mathrm{W}$ artykule przedstawiono wstępne badania belek stalowych wzmocnionych naprężonymi taśmami CFRP. Głównym celem badań była ocena nośności po wzmocnieniu belek taśmami. Badania przeprowadzono na belkach walcowanych o rozpiętości teoretycznej przęsła 4,80 m. Belki wzmocniono taśmami naprężonymi do $40 \%$ i $50 \%$ ich wytrzymałości na rozciąganie. W wyniku wzmocnienia uzyskano odpowiednio 9\% i 10\% wzrost nośności granicznej oraz $11 \%$ i $14 \%$ redukcję ugięć sprężystych. Wykazano, że zwiększenie poziomu wstępnych naprężeń w taśmie miało niewielki wpływ na nośność doraźną belek stalowych.
\end{abstract}

Słowa kluczowe: wzmacnianie konstrukcji, taśmy CFRP, sprężanie, konstrukcje stalowe, nośność doraźna

\section{Wprowadzenie}

Materiały kompozytowe z włókien węglowych (CFRP - Carbon Fiber Reinforced Polymer) są coraz częściej stosowane w budownictwie szczególnie do wzmacniania i napraw obiektów mostowych. Wzmocnienie rozciąganych elementów konstrukcji za pomocą taśm kompozytowych CFRP może zwiększyć ich nośność, ograniczyć nadmierne odkształcenia i zredukować ugięcia.

Doświadczenia zdobyte we wzmacnianiu belek stalowych taśmami CFRP potwierdzają szeroki zakres efektywności tej metody w zależności od właściwości kompozytu, przekroju i długości taśm, a także sposobu wzmocnienia, tj. bierne lub czynne. Jednocześnie efektywność wzmocnienia może zależeć od wymiarów wzmacnianego elementu. Gdy przekrój taśmy stanowi tylko niewielką część przekroju belki, taka zmiana nie może wpłynąć na zmianę momentu bezwładności, a co za tym idzie - sztywności belki.

\footnotetext{
${ }^{1}$ Paulina Paśko, Politechnika Rzeszowska, Zakład Dróg i Mostów, ul. Poznańska 2, 35-049 Rzeszów, tel. (17) 8651 596,ppasko@prz.edu.pl
} 
Badania zginanych belek stalowych wzmocnionych przy użyciu taśm wykazały, że możliwe jest zwiększenie nośności granicznej przekroju od 18\% [1] do $56 \%$ [2]. W świetle badań doświadczalnych wartości te wydają się satysfakcjonujące. W cytowanych pracach badano jednak belki w skali laboratoryjnej, których stopień zbrojenia kompozytowego wynosił min. 5-7\%. Z punktu widzenia praktycznych zastosowań taśm, na przykład do wzmocnień obiektów mostowych, których przekroje są zwykle kilka razy większe, uzyskanie tak wysokich wartości może okazać się niemożliwe. Efektywność wzmocnienia oraz wykorzystanie kompozytu można zwiększyć poprzez wstępne naprężenie taśm. Tezę te potwierdzają liczne badania przeprowadzone na elementach żelbetowych [4], [6]. Jak dotąd zastosowanie wstępnie naprężanych taśm do wzmacniania belek stalowych zostało zbadane w ograniczonym zakresie [7].

$\mathrm{W}$ artykule przedstawiono wybrane wyniki badań wstępnych belek stalowych wzmocnionych czynnie taśmami CFRP. Poprzez porównanie przemieszczeń, odkształceń oraz obciążeń niszczących poszczególnych belek oceniono wzrost nośności doraźnej po wzmocnieniu. Przedstawione badania są kontynuacją prac nad efektywnością wzmocnienia belek stalowych taśmami CFRP, opisanych w pracy [3].

\section{Opis badań}

\subsection{Charakterystyka badanych belek}

Badania przeprowadzono na trzech belkach stalowych o przekroju dwuteowym typu HEB 280 (rys. 1). Belki zostały wykonane ze stali klasy S355J2. Rozpiętość teoretyczna przęsła wynosiła $4,80 \mathrm{~m}$. Belki wzmocniono żebrami pionowymi w przekrojach podporowych oraz w dwóch przekrojach bezpośrednio pod obciążeniem siłami skupionymi. Dodatkowo belki zabezpieczono przed zwichrzeniem poprzez wykonanie w środku rozpiętości przęsła i przy podporach obustronnych bocznych stężeń. Pierwszą belkę (S1) pozostawiono bez wzmocnienia jako referencyjną. Kolejne dwie belki (S4, S6) wzmocniono na zginanie przy użyciu wstępnie naprężonych taśm CFRP. Do tego celu wykorzystano nowy system wzmacniania konstrukcji budowlanych o skróconej nazwie NPS II [5]. Zastosowano taśmy kompozytowe $\mathrm{z}$ włókien węglowych o wymiarach przekroju 1,4 mm (grubość) x $60 \mathrm{~mm}$ (szerokość) i długości (razem z zakotwieniami) ok. 4,35 m. Właściwości mechaniczne taśm określono doświadczalnie na podstawie testów jednoosiowego rozciągania. Średnie wartości właściwości mechanicznych taśm wyniosły: wytrzymałość na rozciąganie $3280 \mathrm{MPa}$, moduł Younga $160 \mathrm{GPa}$, graniczne odkształcenie $20,1 \%$ o. W belce $\mathrm{S} 4$ taśmę naprężono siłą o wartości ok. $111 \mathrm{kN}$. Wartość siły odpowiadała 40,1\% średniej wytrzymałości na rozciąganie kompozytu $\left(\mathrm{f}_{\mathrm{u}}\right)$. W belce $\mathrm{S} 6$ poziom siły sprężającej wynosił ok. $141 \mathrm{kN}\left(50,9 \% \mathrm{f}_{\mathrm{u}}\right)$. Naprężone taśmy zakotwiono w konstrukcji za pomocą fabrycznie wykonanych stalowych zakotwień, będących elementem systemu wzmacniania NPS II i przyklejono do rozciąganych pasów belek za pomocą dwuskładnikowego kleju na bazie modyfikowanej żywicy epoksydowej. 


\subsection{Metodyka badawcza}

Badania zostały przeprowadzone na specjalnie przygotowanym stanowisku badawczym (rys. 1). Swobodnie podparte belki obciążano w schemacie czteropunktowego zginania. Obciążenie w postaci dwóch sił skupionych przyłożono w odległości 1,8 m od osi podparć belek. Rozstaw sił skupionych na długości belki wynosił $1,20 \mathrm{~m}$. Obciążenie generowane było za pomocą 2 siłowników hydraulicznych o maksymalnej sile nacisku $1260 \mathrm{kN}(2 \times 630 \mathrm{kN})$ umieszczonych na stalowej ramie. Badania prowadzono w warunkach kontrolowanego przyrostu siły przy stałym jej wzroście $1 \mathrm{kN} / \mathrm{s}$. Siłę, przemieszczenie tłoka oraz odczyty wskazań czujników rejestrowano z częstotliwością $1 \mathrm{~Hz}$. Pomiar odbywał się w sposób ciągły. Na każdym etapie obciążania monitorowano zachowanie się stref podporowych i łożysk belek. Przemieszczenie pionowe belek w trakcie badań mierzono za pomocą czujników indukcyjnych o bazie pomiarowej $+/-10 \mathrm{~cm}$ oraz $+/-15 \mathrm{~cm}$. Stan odkształceń stali i kompozytu CFRP rejestrowano za pomocą tensometrów elektrooporowych o bazie pomiarowej $+/-10 \mathrm{~mm}$. Schemat rozmieszczenia punktów pomiarowych na belkach S1 oraz S4 i S6 przedstawiono na rys. 2.

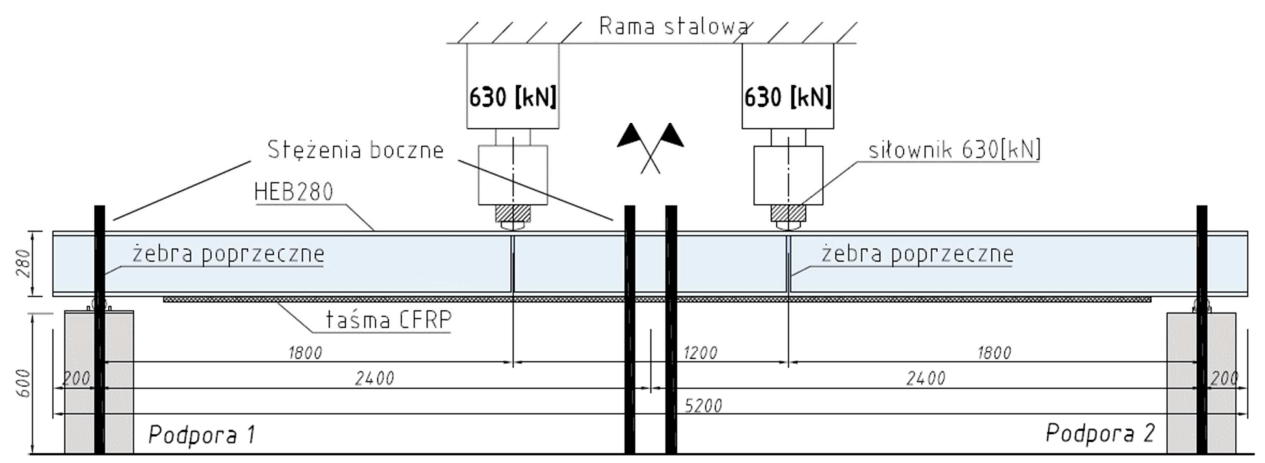

Rys. 1. Schemat stanowiska do badań belek

Fig. 1. Test setup

\section{Wyniki badań}

\subsection{Przemieszczenia belek}

Na rys. 3 przedstawiono wykres zależności ,obciążenie $2 \mathrm{P}$ - przemieszczenie" (2P- $\delta$ ) dla wszystkich 3 belek w środku rozpiętości. W belce S1 w ostatnim etapie obciążania, po osiągnięciu siły $2 \mathrm{P}=\mathrm{ok}$. $600 \mathrm{kN}$, obserwowano przyrost przemieszczeń (z $42 \mathrm{~mm}$ do $50 \mathrm{~mm}$ ) bez wzrostu siły. Wartość tę przyjęto jako obciążenie niszczące belkę S1. W belkach S4 oraz S6 zniszczenie wzmocnienia widoczne jest na wykresie w postaci gwałtownego spadku wartości siły. Całkowite zarejestrowane ugięcie w belce S4 wynosiło wówczas ok. $101 \mathrm{~mm}$ natomiast w belce $S 6$ ok. $103 \mathrm{~mm}$. Po zniszczeniu wzmocnienia obserwowano dalszy przyrost pionowych przemieszczeń belek, przy niewielkim wzroście siły. 

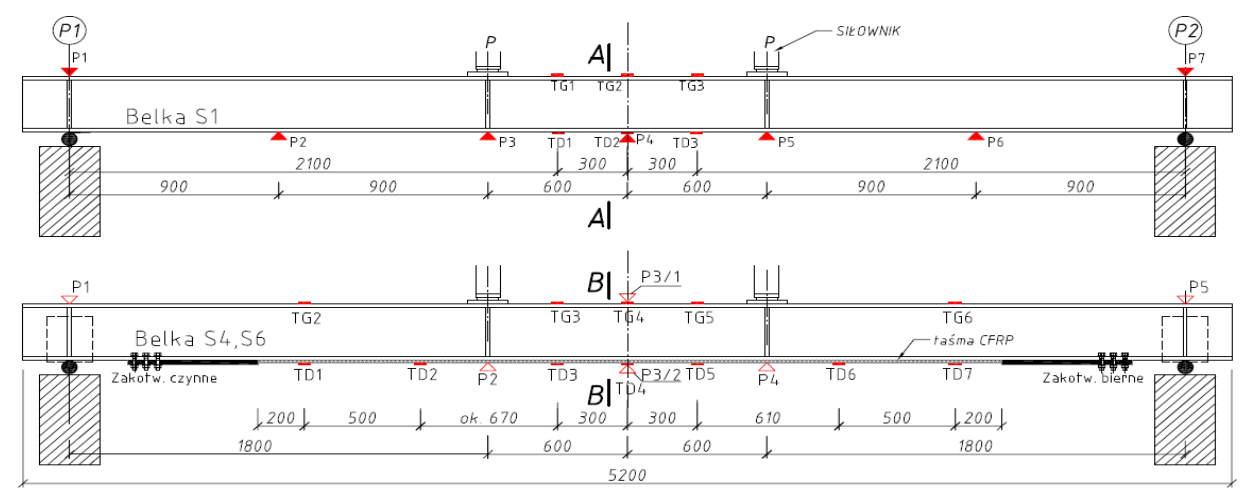

$$
\text { Pas dolny }
$$
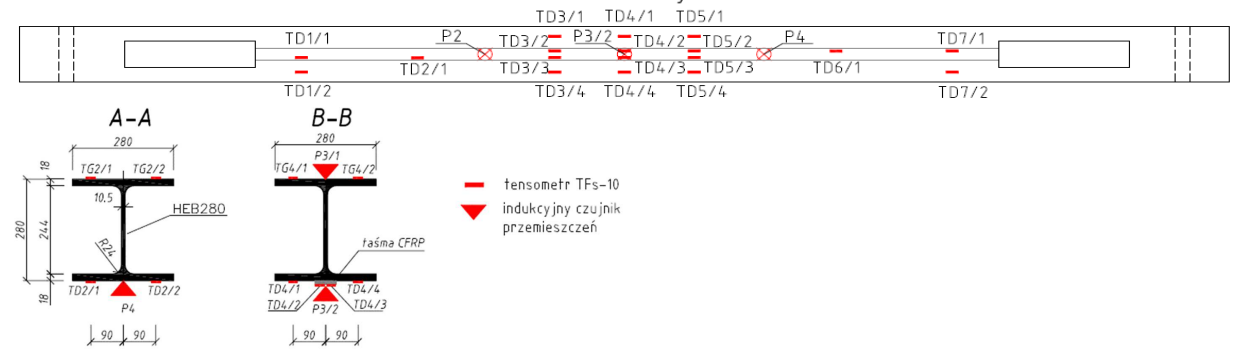

Rys. 2. Lokalizacja czujników przemieszczeń i odkształceń na belkach S1, S4 i S6

Fig. 2. Locations of strain gauges and displacement transducers in beam S1, S4 and S6

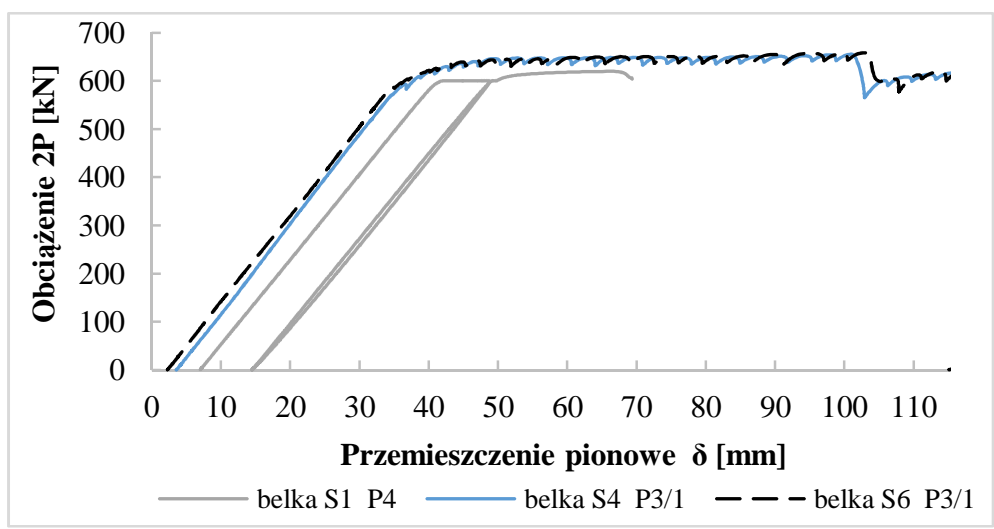

Rys. 3. Wykres 2P- $\delta$ dla belek S1, S4 i S6 w przekroju środkowym przęsła

Fig. 3. Load vs. deflection of beams S1, S4 and S6 at mid-span

W tabeli 1 podano wartości ugięć belek S1, S4 i S6 dla trzech poziomów obciążenia: $400 \mathrm{kN}, 540 \mathrm{kN}$ oraz $600 \mathrm{kN}$ (obciążenie niszczące belkę S1). $\mathrm{W}$ tabeli podano również procentową redukcję ugięć belek $\mathrm{w}$ odniesieniu do belki referencyjnej S1 oraz uzyskaną wskutek zwiększenia poziomu sprężenia. 
Tabela 1. Pionowe przemieszczenia belek S1, S4, S6 w środku rozpiętości przęsła

Table 1. Vertical displacements of beams S1, S4, S6 at mid-span

\begin{tabular}{cccccccc} 
& \multicolumn{3}{c}{$\begin{array}{c}\text { Ugięcia } \\
{[\mathbf{m m}]}\end{array}$ Nr belki } & & & \multicolumn{3}{c}{$\begin{array}{c}\text { Redukcja ugięć } \\
{[\%]}\end{array}$} \\
\cline { 2 - 4 } \cline { 7 - 8 } & $\begin{array}{c}\mathbf{2 P}=\mathbf{4 0 0} \\
{[\mathbf{k N}]}\end{array}$ & $\begin{array}{c}\mathbf{2 P}=\mathbf{5 4 0} \\
{[\mathbf{k N}]}\end{array}$ & $\begin{array}{c}\mathbf{2 P}_{\mathbf{1}}=\mathbf{6 0 0} \\
{[\mathbf{k N}]}\end{array}$ & & $\begin{array}{c}\mathbf{2 P}=\mathbf{4 0 0} \\
{[\mathbf{k N}]}\end{array}$ & $\begin{array}{c}\mathbf{2 P}=\mathbf{5 4 0} \\
{[\mathbf{k N}]}\end{array}$ & $\begin{array}{c}\mathbf{2 P}_{\mathbf{1}}=\mathbf{6 0 0} \\
{[\mathbf{k N}]}\end{array}$ \\
\hline S1 & 23,8 & 34,8 & 42,6 & S1-S4 & $5,5 \%$ & $5,4 \%$ & $\mathbf{1 1 , 4 \%}$ \\
S4 & 22,5 & 32,9 & 37,8 & S1-S6 & $5,0 \%$ & $8,4 \%$ & $\mathbf{1 4 , 4 \%}$ \\
S6 & 22,6 & 31,9 & 36,5 & S4-S6 & $-0,5 \%$ & $3,1 \%$ & $3,4 \%$
\end{tabular}

Porównując wyniki belek S1, S4 i S6 można stwierdzić, że wzmocnienie spowodowało nieznaczną redukcję ugięć w granicach $11 \%$ i $14 \%$. Największe zmiany w wartościach ugięć belek odnotowano przy obciążeniach bliskich granicy plastyczności stali. Na podstawie wykresów, można stwierdzić że ugięcia belek S4 i S6 były prawie jednakowe (różnica ugięć na poziomie 3\%). Wynika $\mathrm{z}$ tego, że zwiększenie siły sprężającej o ok. $10 \%$ miało niewielki wpływ na redukcję pionowych przemieszczeń belek.

\subsection{Odkształcenia stali}

Na rys. 4 i rys. 5 przedstawiono wykresy zależności „obciążenie $2 \mathrm{P}$ - odkształcenie" (2P-ع) skrajnych włókien pasów górnego (ściskanie) i dolnego (rozciąganie) przekroju stalowego w strefie stałego momentu zginającego. Na podstawie przebiegu krzywych odkształceń stali można stwierdzić, że wzmocnienie naprężonymi taśmami powoduje korzystną redukcję odkształceń pod obciążeniem zarówno w pasie górnym jak i dolnym.

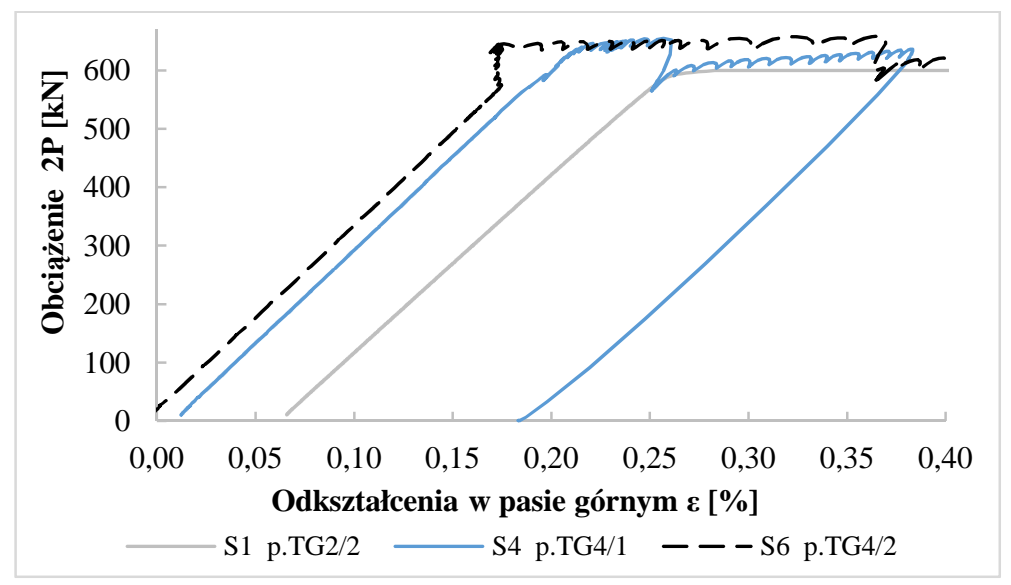

Rys. 4. Wykresy odkształceń stali w pasie górnym belek S1, S4 i S6 w przekroju środkowym

Fig. 4. Strain plots of beams S1, S4, S6 in upper flange at mid-span 


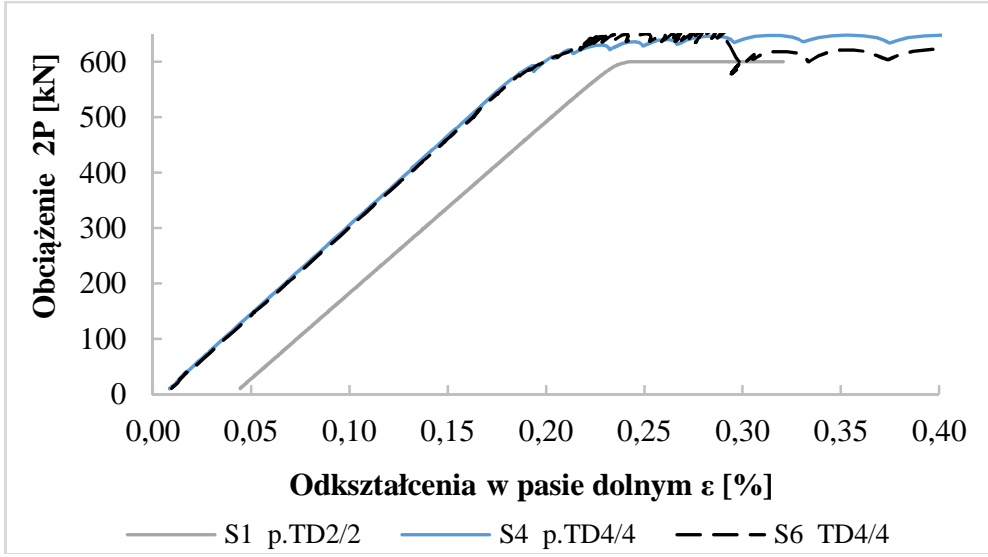

Rys. 5. Wykresy odkształceń stali w pasie dolnym belek S1, S4 i S6 w przekroju środkowym

Fig. 5. Strain plots of beams S1, S4, S6 in lower flange at mid-span

Różnica w wartościach obciążenia uplastyczniającego belki S4 i S6 jest niewielka (uplastycznienie skrajnych włókien pasów dolnych nastąpiło przy sile ok. 585 i $570 \mathrm{kN}$ odpowiednio w belce S4 i S6). W pasie ściskanym mniejsze odkształcenia, przy tym samym poziomie obciążenia tj. $2 \mathrm{P}=645 \mathrm{kN}$ (po uplastycznieniu) odnotowano w belce S6 sprężonej większą siłą. Może to świadczyć o pozytywnym wpływie poziomu naprężenia taśmy na stopień wzmocnienia belek.

$\mathrm{W}$ ostatnim etapie badań prowadzącym do zniszczenia belek (po uprzednim odciążeniu belek) przy sile $2 \mathrm{P}$ ok. $10 \mathrm{kN}$, odkształcenia stali w pasach belek S4 i S6 były niewiele większe od zera (rys. 4 i rys. 5). Natomiast w belce S1 odkształcenia stali na początku obciążania wynosiły ok. 0,05\% (pas dolny) i 0,07\% (pas górny). Oznacza, to że w wyniku wzmocnienia taśmami w belkach S4 i S6 zwiększył się zakres odkształceń sprężystych.

Średnie wartości odkształceń stali w pasach belek dla trzech poziomów obciążenia 2P tj. $400 \mathrm{kN}, 540 \mathrm{kN}$ i $570 \mathrm{kN}$ przedstawiono w tabeli 2.

Tabela 2. Średnie odkształcenia pasów belek S1, S4, S6 w strefie stałego momentu

Table 2. Mean values steel strains of beams S1, S4, S6 measured at constant moment region

\begin{tabular}{|c|c|c|c|c|c|c|c|c|}
\hline \multirow{2}{*}{$\begin{array}{c}\mathrm{Nr} \\
\text { belki }\end{array}$} & \multicolumn{4}{|c|}{$\begin{array}{c}\text { Odkształcenia* } \\
{[\text { microstrain] }}\end{array}$} & & \multicolumn{3}{|c|}{$\begin{array}{c}\text { Redukcja odkształceń } \\
{[\%]} \\
\end{array}$} \\
\hline & & $\begin{array}{c}2 \mathrm{P}_{\mathrm{el}}=400 \\
{[\mathrm{kN}]}\end{array}$ & $\begin{array}{c}2 P_{\mathrm{el}}=540 \\
{[\mathrm{kN}]}\end{array}$ & $\begin{array}{c}2 \mathrm{P}=570 \\
{[\mathrm{kN}]}\end{array}$ & & $\begin{array}{c}2 \mathrm{P}_{\mathrm{el}}=400 \\
{[\mathrm{kN}]}\end{array}$ & $\begin{array}{c}2 P_{\text {el }}=540 \\
{[\mathrm{kN}]}\end{array}$ & $\begin{array}{c}2 \mathrm{P}=570 \\
{[\mathrm{kN}]}\end{array}$ \\
\hline S1 & \multirow{3}{*}{$\begin{array}{l}\text { Pas } \\
\text { górny }\end{array}$} & -1324 & -2001 & -2229 & S1-S4 & $2,7 \%$ & $10,9 \%$ & $15,3 \%$ \\
\hline S4 & & -1288 & -1782 & -1887 & S1-S6 & $4,0 \%$ & $15,3 \%$ & $19,7 \%$ \\
\hline S6 & & -1271 & -1696 & -1789 & S4-S6 & $1,3 \%$ & $4,9 \%$ & $5,2 \%$ \\
\hline S1 & \multirow{3}{*}{$\begin{array}{c}\text { Pas } \\
\text { dolny }\end{array}$} & 1324 & 2026 & 2183 & S1-S4 & $6,6 \%$ & $13,9 \%$ & $15,3 \%$ \\
\hline $\mathrm{S} 4$ & & 1237 & 1744 & 1850 & S1-S6 & $5,1 \%$ & $13,8 \%$ & $15,4 \%$ \\
\hline S6 & & 1256 & 1745 & 1847 & S4-S6 & $-1,5 \%$ & $-0,1 \%$ & $0,2 \%$ \\
\hline
\end{tabular}




\subsection{Nośność graniczna i postać zniszczenia}

Nośność doraźną (tzn. nośność graniczną) przekroju na zginanie zdefiniowano jako maksymalny moment zginający przenoszony przez belkę stalową w środku rozpiętości $\left(\mathrm{M}_{\mathrm{ult}}\right)$. Stan graniczny nośności w belce $\mathrm{S} 1$ został osiągnięty w wyniku utraty stateczności pasa ściskanego, która nastąpiła przy sile $2 \mathrm{P}$ ok. $600 \mathrm{kN}$. Moment zginający w środku rozpiętości przęsła wywołany tym obciążeniem wynosi $543 \mathrm{kNm}$ i wartość tę przyjęto jako nośność graniczną na zginanie belki referencyjnej. Na krótko przed utratą wzmocnienia w belce $S 4$ tj. przy sile ok. $647 \mathrm{kN}$ obserwowano duży przyrost odkształceń stali zarówno w pasie górnym jak i dolnym. Nośność graniczą belki S4 wyznaczono dla siły niszczącej wzmocnienie $\left(2 \mathrm{P}_{\max }\right)$, która wynosiła ok. $655 \mathrm{kN}$. Moment zginający odpowiadający tej sile wynosi $592 \mathrm{kNm}$, co wskazuje na 9,1\% przyrost nośności granicznej. Po osiągnięciu siły $2 \mathrm{P}_{\max }$ kontynuowano obciążanie belki. W końcowym etapie badania zaobserwowano miejscowe wyboczenie pasa górnego w środkowej strefie między żebrami. Maksymalna wartość siły $\left(2 \mathrm{P}_{\max }\right)$ jaką zarejestrowano w badaniach belki S6 wynosiła $658 \mathrm{kN}$. Moment zginający wywołany tą siłą wynosi ok. $595 \mathrm{kNm}$, co wskazuje na 9,6\% przyrost nośności granicznej. Po osiągnięciu $2 \mathrm{P}_{\max }$ nastąpił niewielki spadek sił w obu siłownikach, po czym nastąpiło zniszczenie kompozytu (ok. $650 \mathrm{kN}$ ). Na chwilę przed zniszczeniem wzmocnienia odnotowano gwałtowny i nierównomierny przyrost odkształceń w przekroju stalowym (w obu pasach). W końcowej fazie badania tzn. po zniszczeniu wzmocnienia obserwowano dalszy wzrost odkształceń stali bez wzrostu siły z widocznym wyboczeniem pasa górnego. Zbliżone wartości nośności granicznej w belkach wzmocnionych mogą świadczyć o tym, że zwiększenie stopnia sprężenia o ok. $10 \%$ miało niewielki wpływ na jej wartość.

Podczas badań analizowano towarzyszące maksymalnym obciążeniom postacie zniszczenia. W belce $\mathrm{S} 4$ podłużne pęknięcie taśmy związane było ze zniszczeniem skleiny poddanej nadmiernym odkształceniom i z gwałtownym poślizgiem w zakotwieniu. Mechanizm zniszczenia w belce S6 został zapoczątkowany pęknięciem taśmy na skutek przekroczenia odkształceń granicznych kompozytu. Zniszczenie wzmocnienia następowało stopniowo i miało postać podłużnych i poprzecznych pęknięć na długości taśmy.

\section{Podsumowanie}

W pracy opisano wstępne badania belek stalowych wzmocnionych na zginanie naprężonymi taśmami CFRP. Głównym celem badań była ocena nośności doraźnej belek stalowych po wzmocnieniu. Na podstawie badań stwierdzono, że wzmocnienie naprężonymi taśmami CFRP pozytywnie wpływa na nośność belki stalowej. Wzmocnienie taśmami spowodowało redukcję ugięć belek, która wynosiła odpowiednio 11\% i 14\% w belkach S4 i S6. Zaobserwowano również redukcję odkształceń w ściskanych pasach górnych belek w granicach 15\% (S4) 
i $19 \%$ (S6) oraz ok. $15 \%$ redukcję odkształceń w pasach rozciąganych obu wzmocnionych belek. Ze względu na niewielki stopień zbrojenia kompozytowego, który w tym przypadku wynosił $0,6 \%$ uzyskano jedynie $9 \%$ (w belce S4) i 10\% (w belce S6) wzrost nośności granicznej.

Dokonano również wstępnej oceny wpływu stopnia naprężenia taśmy na efektywność wzmocnienia. W obu przypadkach uzyskano zbliżone wartości przemieszczeń, odkształceń stali oraz sił niszczących wzmocnienie $(655 \mathrm{kN}$ i $658 \mathrm{kN}$ ). Inne są natomiast odkształcenia pasów górnych oraz postacie zniszczenia. Zwiększenie siły sprężającej w belce S6 spowodowało ok. 5\% redukcję odkształceń stali w odniesieniu do belki S4. Tylko w tym zakresie wykazano nieznacznie większą efektywność wzmocnienia na zginanie belek stalowych dla taśmy o większym poziomie naprężenia (S6).

Opisane w artykule badania zostały wykonane w ramach projektu pt.: "Innowacyjny system wzmacniania konstrukcji budowlanych naprężonymi taśmami z kompozytów węglowych", nr projektu POIG.01.03.01-18-010/12, realizowanego w Programie Operacyjnym Innowacyjna Gospodarka (POIG). Projekt był współfinansowany przez Unię Europejską ze środków Europejskiego Funduszu Rozwoju Regionalnego.

\section{Literatura}

[1] Linghoff D., Al-Emrani M., Kliger R.: Performance of steel beams strengthened with CFRP laminate - part 1: laboratory tests, Composites Part B: Engineering, No. 41 2010, pp. 509-511.

[2] Liu X., Silva P., Nanni A.: Rehabilitation of steel bridge members with FRP composite materials, Proceedings of the First International Conference of Composites in Construction, Porto, 2001, pp. 613-617.

[3] Paśko P.: Badania belek stalowych wzmocnionych taśmami CFRP. Konstrukcje betonowe i metalowe Tom III, Wydawnictwa Uczelniane Uniwersytetu Technologiczno-Przyrodniczego w Bydgoszczy, Bydgoszcz 2015, s. 239-248.

[4] Pellegrino C., Modena C.: Flexural strengthening of real-scale RC and PRC beams with end anchored pretensioned FRP laminates, ACI Structural Journal, Vol. 3, No. 106, 2009, pp. 319-328.

[5] Piątek B., Siwowski T.: Badania statyczne i zmęczeniowe zakotwień sprężonych taśm CFRP do wzmacniania konstrukcji budowlanych, Inżynieria i Budownictwo, Vol. 72, No. 1, 2016, s. 24-28.

[6] Quantrill R.J., Hollaway L.C.:The flexural rehabilitation of reinforced concrete beams by the use of prestressed advanced composite plates, Composites Science and Technology, Vol. 8, No. 58, 1998, pp. 1259-1275.

[7] Rizkalla S., Dawood M., Schnerch D.: Development of a carbon fiber reinforced polymer system for strengthening steel structures, Journal of Composites Part A, Vol. 39, No. 2, 2008, pp. 388-397. 


\section{THE EVALUATION OF CARRYING CAPACITY OF STEEL BEAMS STRENGTHENED WITH PRESTRESSED CFRP PLATES}

\section{S u m m a r y}

High tensile strength, low density, corrosion resistance as well as long fatigue life of CFRP strips are the advantages over conventional materials used for strengthening steel structures. Additionally by pre-tensioning strips the CFRP strengthening effectiveness can be significantly increased. The paper presents a preliminary research on steel beams strengthened with pre-tensioned CFRP strips. The main objective of the research was to evaluate the carrying capacity the beams. Research was carried out on three rolled beams with length span of 4,80 m Tension level in composites was about $40 \%$ and $50 \%$ of ultimate tensile strength CFRP. The ultimate capacity of strengthened beams increased by up $9 \%$ and $10 \%$, while deflection decreased by about $11 \%$ and $14 \%$. Increase of stress level in CFRP strip had moderate influence on carrying capacity steel beams and further research are necessary to examine effect of higher tension levels CFRP strips on it.

Keywords: structural strengthening, CFRP strips, prestressing, steel structures, ultimate flexure capacity

Przestano do redakcji: 07.06.2016 r.

Przyjęto do druku: 30.06.2016 r.

DOI: $10.7862 / \mathrm{rb} .2016 .42$ 